\title{
Effects of Kinesiology Taping on Muscle Strength, Dynamic balance, and Functional Movement in Wrestlers with Chronic Ankle Instability
}

\author{
Lee, Kwang-Jin', An, Keun-Ok ${ }^{2 *}$ \\ ${ }^{1}$ Chungbuk National University, Cheongju, Republic of Korea \\ ${ }^{2}$ Korea National University of Transportation, Chungju, Republic of Korea
}

\begin{abstract}
Received: June 25, 2021

Accepted: August 9, 2021

Published online: October 31, 2021

Keywords:

Chronic Ankle Instability

Dynamic Balance

Functional Movement

Kinesio Taping

Wrestlers

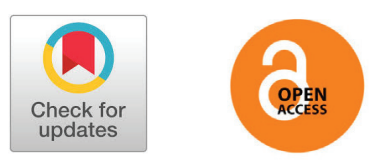

OBJECTIVES This study aimed to investigate the effect of the Kinesio taping on ankle strength, Dynamic balance and, functional movement in wrestlers with chronic ankle instability.

METHODS Twenty wrestlers who registered in the Korea Wrestling Association were participated in this study. They were divided into two groups (chronic ankle instability group [ $=10]$ or control group [ $n=10]$ ) based on Cumberland's ankle instability questionnaire. Ankle strength (dorsiflexion, plantarflexion, inversion, and eversion) were measured using manual muscle tester, and the dynamic balance was measured using Y-Balance test (anterior, postero-medial, postero-lateral, and composite). Functional movement hop test (side hop, square hop, and figure-of-8 hop) were used to evaluate functional movement.

RESULTS The significant interaction was observed between group and time on the $Y$-balance test (composite score), and functional movement hop test (figure-of-8 hop) (group $\times$ time, all P for interaction $<0.05$ ).

CONCLUSIONS These results suggest that Kinesio taping has a positive effect on dynamic balance and functional movement. Also, Kinesio taping may be able to use an alternative and effective methods to maintain ankle stability and performance in the wrestlers with chronic ankle instability.
\end{abstract}

(๑) The Asian Society of Kinesiology and the Korean Academy of Kinesiology

\section{서론}

발목 외측 인대의 손상은 발목 염좌의 대부분을 차 지하며, 초기 치료와 상관없이 급성 외측 염좌(acute lateral sprains)의 10 30\%가 만성 발목 불안정성 (chronic ankle instability; CAI)으로 진행될 수 있 다[1]. CAI는 발목의 반복적인 부상 또는 휘청거림 (giving away)을 인지하는 상태를 말하며, 통증과 약 해짐(weakness) 및 관절운동범위의 감소와 같은 증상 들이 지속되고, 초기 손상 후 1 년 이상 지속되는 재발 성 발목 염좌의 특징을 가진 질환이다[2]. CAI의 원인

\section{Correspondence:}

* An, Keun-Ok, Sports Medicine Major, Division of Sports, Korea National University of Transportation, Chungju, Korea; Tel: +82-43-841-5995; E-mail: koan@ut.ac.kr
은 급성 발목 염좌 이후 인대 조직의 불충분한 치유 및 치료 과정으로 인해 기계적 관절이완(joint laxity)과 운 동감각(sense of movement), 관절 위치감각(sense of joint position) 및 고유수용감각(proprioception)의 손 상 때문인 것으로 알려져 왔다 $[3,4]$.

Kunugi 등 [5]은 CAI 증상이 있는 축구 선수의 경우 엉덩관절 모음, 무릎관절 굽힘과 가쪽돌림, 발목관절 등쪽굽힘 각도 및 엉덩관절 모음근과 종아리 근의 활성 도가 감소되면서 축구 경기력에 영향을 미친다고 보고 하였으며, $\mathrm{CAI}$ 는 짧은 종아리 근과 긴 종아리 근 및 앞 정강 근의 반응 시간을 증가시켜 농구선수의 자세 제어 능력에 부정적으로 영향을 미칠 수 있다고 하였다[6]. 또한 상대방과의 접촉이 빈번하게 발생되는 투기 종목 
선수들에게서 발목 손상의 비중이 높기 때문에 CAI로 이어질 가능성 있으며[7], CAI에 의해 증가된 무릎관 절의 폄과 안쪽 돌림은 엉덩정강근막띠 증후군, 슬개대 퇴통증 증후군 및 앞 십자인대 손상에 영향을 미칠 수 있다[8]. 따라서 경기력 향상과 발목 손상 예방을 위해 운동선수들의 CAI를 정확히 평가할 필요가 있으며, 평 가를 바탕으로 발목 기능을 향상시킬 수 있는 중재 방 법에 대한 효과를 종목의 특성을 반영하여 검토 필요가 있다고 판단된다.

Cumberland의 발목 불안정 도구(Cumberland Ankle Instability Tool; CAIT)는 CAI의 증상과 심각성, 발목의 재 손상 및 외측 발목 염좌 이후 CAI 증상 유무 를 확인하기 위한 설문도구이며, 임상 평가 도구를 통해 쉽게 진단할 수 있는 기계적 발목 불안정성(mechanical ankle instability, MAI) 보다 근·신경계 손상과 같은 기 능적 발목 불안정성(functional ankle instability, FAI) 을 진단하는데 적합한 평가 방법이다[9]. 정재원 등 [10] 은 CAIT가 레슬링 선수의 FAI를 진단하는데 효과적이 며, $\mathrm{FAI}$ 는 레슬링 선수의 근력과 균형능력을 감소시키 고 운동 수행력과 기능을 평가하는 Hop test에 부정적인 영향을 미치는 것으로 보고하였다[11]. 따라서 CAI를 개선하기 위한 방법들을 구체적으로 적용하기 위해서는 CAIT을 포함한 근력 및 기능적 수행력을 평가하여 정확 한 발목의 상태를 확인할 필요가 있다고 판단된다[12].

한편, 키네시오 테이핑(Kinesio Taping, KT)은 운 동 중 근육과 관절을 보호할 수 있으며, 급성 손상과 만성 손상을 예방하는데 효과적이다[13]. Aktas \& Baltaci[14]는 KT가 근력과 기능적 수행력 개선에 효 과적이며, 축구 선수의 무를 근기능 개선[15], 빙상 선 수의 부상 예방과 수행력 강화[16] 및 오버헤드 스포츠 종목 선수들의 견갑골 운동 이상증 개선과 근력 강화에 효과가 있다고 보고하였다[17]. 이밖에 Sarvestan 등 [18]은 KT가 CAI 증상이 있는 대학 운동선수들의 발목 관절 안정성을 증가시키고, 발목의 외측 움직임이 요구 되는 동작의 운동 수행력 개선에 효과적이라고 보고하 였다[19]. 따라서 KT는 CAI가 있는 다양한 종목의 운 동선수에 게 적용이 가능하며, 발목관절의 손상률이 가장 높게 나타나는 종목 중 하나인 레슬링 선수들을 대상으 로 $\mathrm{KT}$ 효과를 실천적으로 검토할 필요가 있다[20, 21].

따라서 이 연구에서는 $\mathrm{KT}$ 가 $\mathrm{CAI}$ 증상이 있는 레슬 링 선수의 근력, 평형성 및 기능적 수행력에 미치는 영
향을 검토하는데 그 목적이 있다.

\section{연구방법}

\section{1. 연구대상}

이 연구에는 2020년 11월 기준 대한 레슬링 협회 에 선수로 등록된 20명을 연구 대상자로 선정하였으 며, 만성 발목 불안정 대상자를 선별할 수 있는 설문지 인 Cumberland의 발목 불안정 도구(CAIT)를 사용하 였다. 만성 발목 불안정 집단(chronic ankle instability group; CAIG, n=10)은 Cumberland의 발목 불안정성 평가 점수가 24점 이하이며, 통제집단(control group; $\mathrm{CG}, \mathrm{n}=10$ )은 24 점 이상이다. 연구 대상자들 중 최근 6 개월 동안 하지 부상, 골절 및 수술 경험이 있을 경우 실 험에서 제외하였다. 모집된 대상자들에게 실험 전 연구 의 과정, 내용 및 목적에 대해 충분히 설명하였으며, 실 험에 참여 의사가 있는 대상자들에게 연구 동의서에 서 명을 받고 진행하였다[22]. 대상자들의 신체적 특성은 <Table 1 >에 제시된 바와 같다.

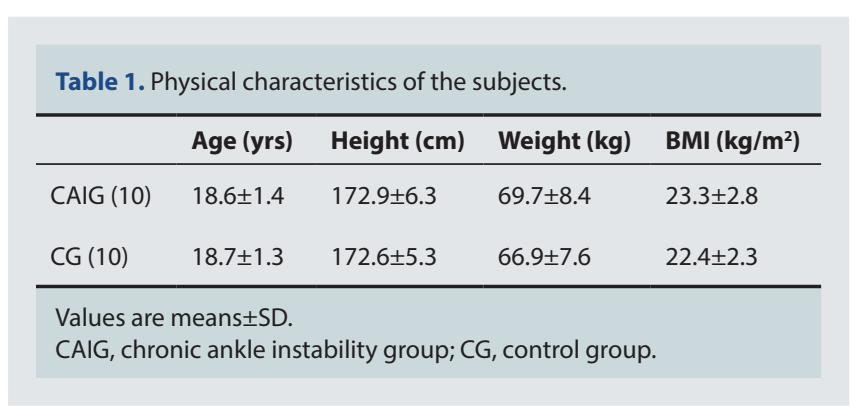

\section{2. 실험절차}

이 연구에서는 레슬링 선수 20 명을 대상으로 사전에 발목 근력, 균형감각 및 기능적 움직임을 측정하였으며, $\mathrm{CAI}$ 집단에 $\mathrm{KT}$ 를 처치하고 48시간 후에 사전 검사와 동일한 방법으로 사후 검사를 실시하였다 $[23,24]$. 테 이핑 적용방법은 < Figure 1 >과 같다.

\section{3. 측정 항목 및 방법}

\section{1) 발목 근력}

대상자의 등척성 발목 근력을 측정하기 위해 휴 대용 근력 측정기(Lafayette Instrument Company, Lafayette, IN, US)를 사용하였으며, 발목의 등쪽 굽 힘, 발바닥 굽힘, 안쪽 번짐 및 가쪽 번짐 근력을 측정하 


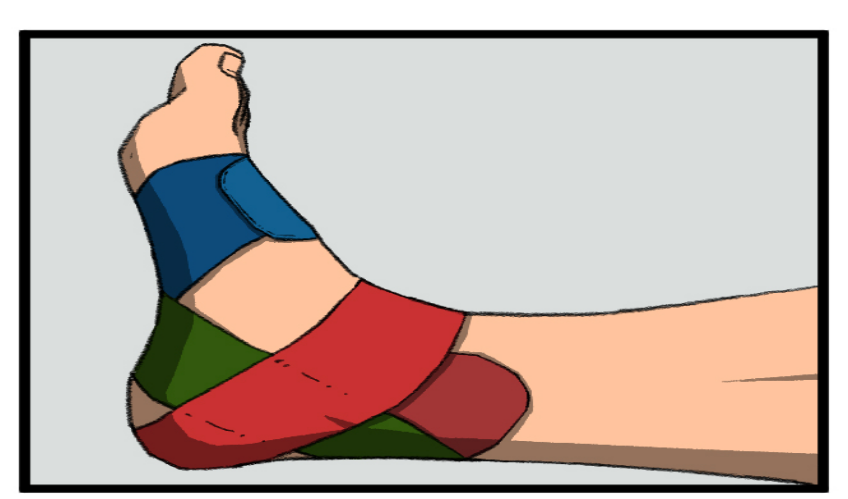

Figure 1. Application method of the kinesio taping.

였다. 대상자의 근력을 측정하기 전에 측정도구 및 측 정용 베드를 조정하였으며, 측정 방향에 대해 정확하게 힘을 줄 수 있도록 교육하였다. 발목의 등쪽 굽힘과 발 바닥 굽힘 근력을 측정하기 위해 휴대용 근력 측정기는 발 허리뼈(metatarsal) 근처의 발등과 발바닥에 위치 시 켰으며, 대상자를 측정용 베드에 반듯이 눕힌 상태에서 무릎을 완전히 펴고 발목관절을 중립 시킨 후 측정하였 다. 안쪽 번짐과 가쪽 번짐은 동일한 위치에 있는 대상 자를 대상으로 평가하였으며, 첫 번째와 다섯 번째 발 허리뼈의 중간 지점에 근력 측정기를 위치시켜 각각 측 정하였다. 대상자는 각각의 방향에서 2 회 측정하였으 며, 각 측정마다 5 초간 등척성 수축을 지속하도록 하였 다. 측정 사이의 간격은 30 초로 설정하였으며, 검사 중 잘못된 움직임이 발견되었을 때 20초의 휴식을 부여하 고 재 측정하였다[22].

\section{2) 균형감각}

대상자의 균형감각 평가는 $\mathrm{Y}$-Balance test 방법을 이용하였으며, 직사각형 형태의 중심 발판을 기준으로 앞쪽(anterior, AN)과 후 내측(posteromedial, PM) 및 후 외측(posterolateral, PL) 방향에 3 개의 파이프가 장착되어 있는 Y-Balance Test Kit (Move2 Perform, Evansville, IN, USA)을 사용하여 측정하였다. AN 파 이프는 $\mathrm{PM}$ 과 $\mathrm{PL}$ 파이프와 각각 $135^{\circ}$ 떨어져 있으며, $\mathrm{PM}$ 과 $\mathrm{PL}$ 파이프는 $90^{\circ}$ 간격으로 배치되어 있다. 또한 각 파이프에 거리를 측정할 수 있는 3 개의 발판을 통해 중심 발판에서 3 개의 발판이 얼마나 멀리 위치했는지 측 정하였다. 실험 전 모든 대상자는 Y-Balance test 방법 을 익히기 위해 3 번씩의 연습 기회를 부여하였으며, 측 정 중 주의사항에 대해 교육하였다. 대상자는 $\mathrm{AN}, \mathrm{PM}$
및 $\mathrm{PL}$ 의 도달 거리를 2회 측정하였으며, 3 가지 방향의 도달 거리를 합산한 종합점수(composite score)도 사 용하였다[25].

$$
\begin{aligned}
{[\text { composite score }=} & \{(\mathrm{AN}+\mathrm{PM}+\mathrm{PL}) /(3 \times \operatorname{limb} \\
& \text { length })\} \times 100] .
\end{aligned}
$$

\section{3) 기능적 움직임}

대상자의 기능적 움직임 측정은 Side hop, Figureof-8 hop 및 Square hop 검사를 실시하였다. Side hop 는 $30 \mathrm{~cm}$ 간격으로 표시된 선을 좌·우로 10 회 왕복하는 데 걸리는 시간을 측정하였으며, 대상자는 2 회 실시하 였다. Figure-of-8 hop는 $5 \mathrm{~m}$ 간격으로 원뿔 콘을 배치 한 후 출발선에 있는 원뿔 콘에서부터 반대쪽에 있는 원 뿔 콘을 8자 모양으로 돌아오는 시간을 측정하였으며, 대상자는 2 회 실시하였다. Square hop 는 바닥에 표시 된 $40 \mathrm{~cm} \times 40 \mathrm{~cm}$ 의 정사각 면을 바깥쪽에서 안쪽, 안 쪽에서 바깥쪽으로 뛰어넘는 방법으로 시계방향 또는 시계 반대 방향으로 정사각형의 4 면을 총 5 회 반복해 야 하며, 대상자는 2 회 실시하였다. 측정 중 선을 밟거 나 넘어지는 경우에는 3 분간의 휴식을 부여한 후 재 측 정하였다[26].

\section{4. 통계처리}

이 연구의 자료처리는 SPSS 23.0(SPSS Inc., Chicago, IL, USA)을 이용하여 기술 통계치 (Means $\pm \mathrm{SD}$ )를 산출하였다. 만성 발목 불안정 집단 $(\mathrm{CAIG})$ 과 통제집단 $(\mathrm{CG})$ 차이를 비교 분석하기 위하여 반복 측정 변량분석(repeated measure ANOVA)을 실 시하였으며, 사후 검증은 $\mathrm{T}$-test를 실시하였다. 모든 통 계적 유의 수준은 $a=.05$ 로 설정하였다.

\section{연구 결과}

\section{1. 근력}

근력은 <Table 2>에 제시한 바와 같다. 발목의 등 쪽 굽힘, 발바닥 굽힘, 안쪽 번짐 및 가쪽 번짐은 집단과 시기 간에 상호작용 효과가 나타나지 않았다. 가쪽 번 짐의 시기 간 $(F=8.205, p=.010)$ 과 집단 간 $(F=5.467$, $p=.031)$ 에서는 유의한 차이가 나타났으며, 나머지 변 인은 시기 간과 집단 간에서 유의한 차이가 나타나지 않았다. 
Table 2. Change of ankle muscle strength.

\begin{tabular}{|c|c|c|c|c|c|c|}
\hline & Group & Pre & Post & Group & $\boldsymbol{F}$ & $p$ \\
\hline \multirow{3}{*}{$\begin{array}{l}\text { Dorsi flexion } \\
(\mathrm{N} \cdot \mathrm{m})\end{array}$} & CAIG & $13.5 \pm 2.8$ & $14.0 \pm 2.4$ & $\mathrm{~T}$ & 1.126 & .303 \\
\hline & CG & $14.2 \pm 3.1$ & $14.2 \pm 2.8$ & G & .135 & .717 \\
\hline & & & & $T^{*} G$ & 1.572 & .226 \\
\hline \multirow{3}{*}{$\begin{array}{l}\text { Plantar flexion } \\
(\mathrm{N} \cdot \mathrm{m})\end{array}$} & CAIG & $10.3 \pm 3.1$ & $11.0 \pm 3.4$ & $\mathrm{~T}$ & 2.753 & .114 \\
\hline & CG & $13.0 \pm 2.8$ & $13.0 \pm 2.8$ & G & 3.105 & .095 \\
\hline & & & & $T^{*} G$ & 3.428 & .081 \\
\hline \multirow{3}{*}{$\begin{array}{l}\text { Eversion } \\
(\mathrm{N} \cdot \mathrm{m})\end{array}$} & CAIG & $5.8 \pm 1.2$ & $6.2 \pm 1.1$ & $\mathrm{~T}$ & 8.205 & $.010^{*}$ \\
\hline & CG & $6.9 \pm 0.7$ & $7.1 \pm 0.9$ & G & 5.467 & $.031^{*}$ \\
\hline & & & & $T^{*} G$ & 1.469 & .241 \\
\hline \multirow{3}{*}{$\begin{array}{l}\text { Inversion } \\
(\mathrm{N} \cdot \mathrm{m})\end{array}$} & CAIG & $7.0 \pm 1.3$ & $7.2 \pm 1.0$ & $T$ & .796 & .384 \\
\hline & CG & $7.4 \pm 1.2$ & $7.3 \pm 1.0$ & G & .275 & .606 \\
\hline & & & & $T^{*} G$ & 1.345 & .261 \\
\hline
\end{tabular}

Values are means $\pm S D$. ${ }^{*} p<.05$

CAIG, chronic ankle instability group; CG, control group. T, time; G, group.

Table 3. Change of balance

\begin{tabular}{|c|c|c|c|c|c|c|}
\hline & Group & Pre & Post & Group & $\boldsymbol{F}$ & $p$ \\
\hline & CAIG & $55.0 \pm 8.7$ & $58.8 \pm 6.5$ & $\mathrm{~T}$ & 3.418 & .081 \\
\hline \multirow[t]{3}{*}{ An $(\mathrm{cm})$} & CG & $61.8 \pm 5.6$ & $61.7 \pm 3.5$ & G & 3.220 & .090 \\
\hline & & & & $T^{*} G$ & 3.797 & .067 \\
\hline & CAIG & $91.1 \pm 13.1$ & $91.2 \pm 10.9$ & $\mathrm{~T}$ & .081 & .779 \\
\hline \multirow[t]{3}{*}{$\mathrm{PM}(\mathrm{cm})$} & CG & $93.9 \pm 10.1$ & $93.3 \pm 7.9$ & G & .271 & .609 \\
\hline & & & & $T^{*} G$ & .159 & .695 \\
\hline & CAIG & $86.7 \pm 10.9$ & $89.4 \pm 9.4$ & $\mathrm{~T}$ & 2.939 & .104 \\
\hline \multirow[t]{3}{*}{$\mathrm{PL}(\mathrm{cm})$} & CG & $96.5 \pm 7.1$ & $96.4 \pm 6.3$ & G & 4.855 & $.041^{*}$ \\
\hline & & & & $T^{*} G$ & .409 & .081 \\
\hline & CAIG & $86.2 \pm 9.3$ & $88.7 \pm 6.0$ & $\mathrm{~T}$ & 2.984 & .101 \\
\hline \multirow[t]{2}{*}{$\begin{array}{l}\text { Composite } \\
(\%)\end{array}$} & CG & $94.1 \pm 6.2$ & $93.8 \pm 5.3$ & G & 4.620 & $.045^{*}$ \\
\hline & & & & $T^{*} G$ & 4.791 & $.042^{*}$ \\
\hline
\end{tabular}

Values are means \pm SD. ${ }^{*} p<.05$

CAIG, chronic ankle instability group; CG, control group. T, time; G, group.

\section{2. 균형감각}

균형감각은 <Table $3>$ 에 제시한 바와 같다. $\mathrm{Y}$-Balance test의 종합점수 $(\mathrm{F}=4.791, \mathrm{p}=.042)$ 는 집 단과 시기 간에 상호작용 효과가 나타났지만, $\mathrm{AN}, \mathrm{PM}$ 및 $\mathrm{PL}$ 에서는 집단과 시기 간에 상호작용 효과가 나타 나지 않았다. 집단 간에서는 $\mathrm{PL}(F=4.855, p=.041)$ 과 종합점수 $(F=4.620, p=.045)$ 에서 유의한 차이가 나타 났으며, 시기 간에서는 유의한 차이가 나타나지 않았다.

\section{3. 기능적 움직임}

기능적 움직임은 <Table $4>$ 에 제시한 바와 같다. Figure-of-8 hop ( $F=6.440, p=.021)$ 은 집단과 시기 간 에 상호작용 효과가 나타났지만, Side hop, Square hop 은 집단과 시기 간에 상호작용 효과가 나타나지 않았다. 시기 간에서는 Figure-of-8 hop $(F=5.719, p=.028)$ 에 서만 유의한 차이가 나타났으며, 집단 간은 유의한 차이 가 나타나지 않았다. 


\begin{tabular}{|c|c|c|c|c|c|c|}
\hline & Group & Pre & Post & Group & $\boldsymbol{F}$ & $p$ \\
\hline \multirow{3}{*}{$\begin{array}{l}\text { Side hop } \\
\text { (sec) }\end{array}$} & CAIG & $9.7 \pm 1.0$ & $9.4 \pm 1.0$ & $\mathrm{~T}$ & .291 & .596 \\
\hline & CG & $9.4 \pm 0.9$ & $9.3 \pm 0.8$ & G & .202 & .658 \\
\hline & & & & $T^{*} G$ & .206 & .656 \\
\hline \multirow{3}{*}{$\begin{array}{l}\text { Square hop } \\
\text { (sec) }\end{array}$} & CAIG & $17.5 \pm 1.2$ & $17.4 \pm 0.9$ & $\mathrm{~T}$ & 3.281 & .087 \\
\hline & CG & $17.2 \pm 1.6$ & $17.1 \pm 1.7$ & G & .282 & .602 \\
\hline & & & & $T^{*} G$ & 1.323 & .265 \\
\hline \multirow{3}{*}{ Figure-of-8 hop (sec) } & CAIG & $5.7 \pm 1.0$ & $5.4 \pm 0.8$ & $\mathrm{~T}$ & 5.719 & $.028^{*}$ \\
\hline & CG & $5.3 \pm 1.1$ & $5.3 \pm 0.9$ & G & .468 & .503 \\
\hline & & & & $T^{*} G$ & 6.440 & $.021^{*}$ \\
\hline
\end{tabular}

\section{논의}

이 연구에서는 $\mathrm{CAI}$ 증상이 있는 레슬링 선수에게 $\mathrm{KT}$ 를 적용한 후 근력, 평형성 및 기능적 수행력에 미치는 영향을 검토한 결과, 균형감각(Y-Balance test, 종합점 수)과 기능적 움직임(Figure-of-8 hop)에서 유의한 차 이가 나타났다. 따라서 이 연구에서 $\mathrm{KT}$ 적용이 CAI가 있는 레슬링 선수의 균형감각과 기능적 움직임 개선에 긍정적인 영향을 미친다는 사실을 확인하였다.

레슬링 선수의 하지 손상은 빈번하게 발생되고, 발목 의 재 손상은 비교적 높은 비율을 차지하고 있으며, 발 목의 급성 손상 후에 나타나는 만성 손상은 레슬링 선수 의 발목 주변 근육의 힘을 감소시킨다[10]. Elshemy와 Battecha[27]는 CAI로 인해 감소된 발목 근력을 강화 하기 위한 중재 방법으로 근력 및 고유수용감각 훈련과 함께 테이핑 적용을 강조하였지만, Csapo 등[28]은 테 이핑 적용을 통한 근력의 향상은 논쟁의 여지가 있는 것 으로 보고하였다. 이 연구에서 $\mathrm{KT}$ 적용 후에 등쪽 굽힘, 발바닥 굽힘, 안쪽 번짐 및 가쪽 번짐은 유의한 차이가 나타나지 않았다. 하지만 Christou[29]는 테이핑 적용 이 진피 속의 제 2 형의 기계 수용기를 자극하고 운동 동 원 단위를 증가시켜 근력을 강화 시킬 가능성이 있다고 보고하였으며, 이 연구에서도 외번 근력이 향상되는 경 향성을 나타났기 때문에 추후 연구에서는 테이핑의 종
류, 방법 및 강도 등을 종합적으로 검토하여 분석할 필 요가 있다고 생각한다.

발목 관절의 인대와 관절낭에는 고유수용감각이 많 이 분포되어 있으며, 발목 손상 후 나타나는 고유수용감 각 기능의 결함은 균형 감각을 감소시키고, $\mathrm{CAI}$ 증상을 가속화 시킬 가능성이 있다 $[30,31]$. 특히 CAI 증상이 있는 레슬링 선수는 균형감각이 감소되는 것으로 나타 났다[10, 32]. Lee 등 [8]은 CAI 증상이 있는 운동선수 의 균형능력을 향상시키기 위해 $\mathrm{KT}$ 적용한 결과, 균형능 력을 평가하는 SEBT가 개선되었다고 보고하였다. 또한 Jackson 등 [22]은 KT 적용한 후 48시간이 경과된 후에 $\mathrm{CAI}$ 증상이 있는 20 대의 균형능력이 향상 되었으며, 3 회 6 주간 발목 테이핑 적용과 주 3 회 6 주간 균형 훈련은 젊은 여성의 균형능력 향상에 긍정적인 영향을 미치는 것으로 보고하였다[33]. 이 연구에서 Y-Balance test의 $\mathrm{AN}, \mathrm{PM}$ 및 PL에서는 유의한 차이가 나타나지 않았지만 종합점수에서는 유의한 차이가 나타났다. Lins 등 [34] 은 $\mathrm{KT}$ 를 피부에 부착했을 때 발생되는 장력(tension) 이 발목 운동 시 신경 피드백(Neural feedback)을 증가 시키고, 고유수용감각 기능을 향상시킨다고 보고하여, $\mathrm{CAI}$ 가 있는 레슬링 선수에게 $\mathrm{KT}$ 를 적용한 결과 균형 능력이 개선되었다고 생각된다.

한편, 기능적 움직임 평가는 근골격계 손상이 있는 운동선수 및 일반인의 신체적 능력을 객관화하고 움직 
임에 수반되는 손상 정도를 확인할 수 있으며, 손상 후 스포츠 및 일상생활 복귀 기준을 제시하는데 활용된다 [35]. 기능적 움직임 평가 방법 중에서 Hop test는 하 지의 기능적 움직임을 평가하는 방법이며, CAI를 평가 하기 적합한 측면 점핑 동작들이 반영되어 있다[36]. 선 행연구에 의하면, CAI 증상이 있는 운동선수는 hop test 가 낮은 것으로 나타났으며 [26], 저항 훈련, 균형 훈련 및 테이핑 중재 등이 CAI로 인해 감소된 기능적 움직 임 향상에 효과적인 것으로 보고하였다[37]. Bicici 등 [38]은 CAI 증상이 있는 운동선수와 부상이 없는 운동 선수에게 발목 테이핑을 처치한 결과, 테이핑 처지 전 보다 적용 후에 두 집단 모두 Single leg hoping curse, Figure-of-8 hop 및 Side hop test가 유의하게 향상되 었으며[18], KT의 적용이 Cumberland의 발목 불안정 성 평가 도구에 의해 CAI로 분류된 농구선수의 Figureof-8 hop을 개선했다고 보고하였다. 이 연구에서 Side hop, Square hop에서는 유의한 차이가 나타나지 않았 지만 Figure-of-8 hop에서는 유의한 차이가 나타났다. Murray[39]는 KT가 관절의 위치감각(position sense), 관절 구조 지지 및 고유수용감각 활성화에 관여할 수 있 다고 보고 하여, 결과적으로 CAI가 있는 레슬링 선수 근 육 동원 시간과 자세 조절 능력을 개선하고, 기능적 움 직임에 긍정적으로 영향을 미친 것이라고 생각된다. 또 한 Dastmanesh 등 [40]은 CAI가 발목관절에서 나타나 는 증상이지만 허리, 골반 및 고관절 복합체의 근육 동 원 순서 및 개별 근육의 활성도에 영향을 미칠 수 있기 때문에 운동 사슬 관점에서 $\mathrm{CAI}$ 개선이 필요하다고 하 였으며, An \& Lee[41]는 CAI와 같은 손상을 예방하기 위해서는 기능적 운동과 스포츠 손상 예방이 결합된 기 능적손상예방(functional injury prevention; FIP)프로 그램의 필요성을 강조하였다. 따라서 추후 연구에서는 발목, 허리, 골반 및 고관절 등 다양한 부위에 $\mathrm{KT}$ 의 적 용과 함께 FIP 프로그램이 CAI 예방에 미치는 효과를 규명할 필요가 있다.

\section{결론}

이 연구에서는 KT 적용이 CAI가 있는 레슬링 선수의 근력, 균형감각 및 기능적 움직임에 미치는 영향을 분석 한 결과, 발목 테이핑이 CAI 증상이 있는 레슬링 선수의 균형감각과 기능적 움직임을 긍정적으로 개선한다는 사
실을 증명하였다. 추후 연구에서는 테이핑의 종류, 방법 및 다양한 부위 적용 등에 따른 효과를 상세하게 검토할 필요가 있다고 판단된다.

\section{Acknowledgments}

This was supported by Korea National University of Transportation in 2021.

\section{Conflicts of Interest}

The authors declare no conflict of interest.

\section{References}

1. Renström PA, Lynch SA. Ankle ligament injuries. Rev Bras Med Esporte. 1998; 4(3):71-80.

2. Hertel J, Corbett RO. An updated model of chronic ankle instability. J Athl Train. 2019; 54(6):572-588.

3. Hubbard TJ, Cordova M. Effect of ankle taping on mechanical laxity in chronic ankle instability. Foot Ankle Int. 2010; 31(6):499-504.

4. Raymond J, Nicholson LL, Hiller CE, Refshauge KM. The effect of ankle taping or bracing on proprioception in functional ankle instability: a systematic review and meta-analysis. J Sci Med Sport. 2012; 5(5):386-392.

5. Kunugi S, Masunari A, Koumura T, Fujimoto A, Yoshida N, Miyakawa S. Altered lower limb kinematics and muscle activities in soccer players with chronic ankle instability. Phys Ther Sport. 2018; 34:28-35.

6. Méndez-Rebolledo G, Guzmán-Muñoz E, Gatica-Rojas $\mathrm{V}$, Zbinden-Foncea H. Longer reaction time of the fibularis longus muscle and reduced postural control in basketball players with functional ankle instability: A pilot study. Phys Ther Sport. 2015; 16(3):242-247.

7. Yu JI, Cho YH, Seo TB. Study on the frequency of sports injury and re-injury in combat sports athletes. JKAMA. 2019; 21(4):157-169.

8. Lee E, Cho J, Lee S. Short-foot exercise promotes quantitative somatosensory function in ankle instability: a randomized controlled trial. Med Sci Mon Int Med J Exp Clin Res. 2019; 25:618. 
9. Henderson EM. Evaluation of the Cumberland Ankle Instability Tool as a predictor of ankle re-injury in collegiate athletes(Doctoral dissertation, University of Delaware). 2015.

10. Jeong JW, Seo SW, Park JU, Kim HJ. The Effect of Functional Ankle Instability on Muscle Strength and Functional Movement in Elite Wrestlers. JKAMA. 2020; 22(4):205-214.

11. Choi GJ. The Balance Ability and Functional Performance Ability of College Soccer Players with Ankle Instability. Korea Sport Society. 2013; 11(2):217-225.

12. Park YH, Park SH, Kim SH, Choi GW, Kim HJ. Relationship between isokinetic muscle strength and functional tests in chronic ankle instability. J Foot Ankle Surg. 2019; 58(6):1187-1191.

13. Williams S, Whatman C, Hume PA, Sheerin K. Kinesio taping in treatment and prevention of sports injuries. Sports Med. 2012; 42(2):153-164.

14. Aktas G, Baltaci G. Does kinesio taping increase knee muscles strength and functional performance?. Isokinet Exerc Sci. 2011; 19(3):149-155.

15. De Hoyo M, Álvarez-Mesa A, Sañudo B, Carrasco L, Domínguez S. Immediate effect of kinesio taping on muscle response in young elite soccer players. J Sport Rehabil. 2013; 22(1):53-58.

16. Lee YS, Kwak CS, Lee CL, Kim TG. Effects of lower extremity stability by kinesio taping method in elite speed skating athletes' one-leg jumping. Journal of Digital Convergence. 2015; 13(8):495-502.

17. Ozer ST, Karabay D, Yesilyaprak SS. Taping to improve scapular dyskinesis, scapular upward rotation, and pectoralis minor length in overhead athletes. J Athl Train. 2018; 53(11):1063-1070.

18. Sarvestan J, Ataabadi PA, Svoboda Z, Kovačikova Z, Needle AR. The effect of ankle Kinesio ${ }^{\text {tm }}$ taping on ankle joint biomechanics during unilateral balance status among collegiate athletes with chronic ankle sprain. Phys Ther Sport. 2020; 45:161-167.

19. Someeh M, Norasteh AA, Daneshmandi H, Asadi A. Influence of Mulligan ankle taping on functional performance tests in healthy athletes and athletes with chronic ankle instability. Int J Athl Ther Train. 2015; 20(1):39-45.

20. Shadgan B, Feldman BJ, Jafari S. Wrestling injuries during the 2008 Beijing olympic games. AM J SPORT MED. 2010; 38(9):1870-1876.

21. Kim TW, Choi KJ, Moon YJ, et al. Analysis of Sports Injury Induced Behavior in Summer Sports. Korean J Sport Sci. 2015; 26(4):690-701.

22. Carvalho APDMC. Comparison of isometric ankle strength between females with and without patellofemoral pain syndrome. Int J Sports Phys Ther. 2014; 9(5):628.

23. Jackson K, Simon JE, Docherty CL. Extended use of kinesiology tape and balance in participants with chronic ankle instability. J Athl Train. 2016; 51(1):16-21.

24. Lee SM, Lee JH. The immediate effects of ankle balance taping with kinesiology tape on ankle active range of motion and performance in the Balance Error Scoring System. Phys Ther Sport. 2017; 25:99-105.

25. Lee KJ, Seo KW, An KO. Effects of the Non-Face-ToFace Learning on Health-Related Physical Fitness and Balance in Adolescents According to COVID-19. Exerc Sci. 2021, 30(2), 229-236.

26. Sharma N, Sharma A, Sandhu JS. Functional performance testing in athletes with functional ankle instability. Asian J Sports Med. 2011; 2(4):249.

27. Elshemy SA, Battecha KH. Kinesio taping versus proprioceptive training on dynamic position sense of the ankle and eversion to inversion strength ratios in children with functional ankle instability. Med J Cairo Univ. 2013; 81(2).

28. Csapo R, Herceg M, Alegre LM, Crevenna R, Pieber K. Do kinaesthetic tapes affect plantarflexor muscle performance?. J Sports Sci. 2012; 30(14):1513-1519.

29. Christou EA. Patellar taping increases vastus medialis oblique activity in the presence of patellofemoral pain. J Electromyogr Kinesiol. 2004; 14(4):495-504.

30. Rosenbaum D, Becker HP, Gerngroß H, Claes L. Peroneal reaction times for diagnosis of functional ankle instability. Foot Ankle Surg. 2000; 6(1):31-38.

31. Munn J, Sullivan SJ, Schneiders AG. Evidence of 
sensorimotor deficits in functional ankle instability: a systematic review with meta-analysis. J Sports Sci Med. 2010; 13(1):2-12.

32. Olmsted LC, Carcia CR, Hertel J, Shultz SJ. Efficacy of the star excursion balance tests in detecting reach deficits in subjects with chronic ankle instability. J Athl Train. 2002; 37(4):501.

33. Akbari A. Sarmadi A, Zafardanesh P. The effect of ankle taping and balance exercises on postural stability indices in healthy women. J Phys Ther Sci. 2014; 26(5):763-769.

34. Lins CA, Borges DT, Macedo LB, Costa KS, Brasileiro JS. Delayed effect of Kinesio Taping on neuromuscular performance, balance, and lower limb function in healthy individuals: a randomized controlled trial. Braz J Phys Ther. 2016; 20(3):231-239.

35. Reiman MP, Manske RC. Functional testing in human performance. Illinois, USA. Human Kinetics. 2009, p 247-248

36. Rosen AB, Needle AR, Ko J. Ability of functional performance tests to identify individuals with chronic ankle instability: a systematic review with metaanalysis. Clin J Sport Med. 2019; 29(6):509-522.

37. Kosik KB, McCann RS, Terada M, Gribble PA. Therapeutic interventions for improving self-reported function in patients with chronic ankle instability: a systematic review. Br J Sports Med. 2017; 51(2):105-112.

38. Bicici S, Karatas N, Baltaci G. Effect of athletic taping and kinesiotaping ${ }^{\oplus}$ on measurements of functional performance in basketball players with chronic inversion ankle sprains. Int J Sports Phys Ther. 2012; $7(2): 154$.

39. Murray H. Effect of kinesio ${ }^{\mathrm{TM}}$ taping on proprioception in the ankle. J Orthop Sports Phys Ther. 2001; 31:A-37.

40. Dastmanesh S, Shojaedin SS, Eskandari E. The effects of core stabilization training on postural control of subjects with chronic ankle instability. Ann Biol Res. 2012; 3(8):3926-3930.

41. An KO, Lee KJ. Sports Injury Prevention and Functional Training: A Literature Review. Asian J Kinesiol. 2021; 23(1):46-52. 